\title{
A Glial Endogenous Cannabinoid System Is Upregulated in the Brains of Macaques with Simian Immunodeficiency Virus-Induced Encephalitis
}

\author{
Cristina Benito, ${ }^{1}$ Wong-Ki Kim, ${ }^{2}$ Iván Chavarría, ${ }^{1,3}$ Ceceila J. Hillard ${ }^{4}$ Ken Mackie, ${ }^{5}$ Rosa M. Tolón, ${ }^{1}$ Ken Williams, ${ }^{2}$ and \\ Julián Romero ${ }^{1,3}$ \\ ${ }^{1}$ Laboratorio de Apoyo a la Investigación, Fundación Hospital Alcorcón, 28922 Madrid, Spain, ${ }^{2}$ Division of Viral Pathogenesis, Beth Israel Deaconess \\ Medical Center, Harvard Medical School, Boston, Massachusetts 02215, ${ }^{3}$ Department of Biochemistry, Francisco de Vitoria University, Pozuelo de Alarcón, \\ 28223 Madrid, Spain, ${ }^{4}$ Department of Pharmacology and Toxicology, Medical College of Wisconsin, Milwaukee, Wisconsin 53226, and ${ }^{5}$ Department of \\ Anesthesiology, University of Washington, Seattle, Washington 98195
}

Recent evidence supports the notion that the endocannabinoid system may play a crucial role in neuroinflammation. We explored the changes that some elements of this system exhibit in a macaque model of encephalitis induced by simian immunodeficiency virus. Our results show that profound alterations in the distribution of specific components of the endocannabinoid system occur as a consequence of the viral infection of the brain. Specifically, expression of cannabinoid receptors of the $\mathrm{CB}_{2}$ subtype was induced in the brains of infected animals, mainly in perivascular macrophages, microglial nodules, and T-lymphocytes, most likely of the CD8 subtype. In addition, the endogenous cannabinoid-degrading enzyme fatty acid amide hydrolase was overexpressed in perivascular astrocytes as well as in astrocytic processes reaching cellular infiltrates. Finally, the pattern of $\mathrm{CB}_{1}$ receptor expression was not modified in the brains of infected animals compared with that in control animals. These results resemble previous data obtained in Alzheimer's disease human tissue samples and suggest that the endocannabinoid system may participate in the development of human immunodeficiency virusinduced encephalitis, because activation of $\mathrm{CB}_{2}$ receptors expressed by immune cells is likely to reduce their antiviral response and thus could favor the CNS entry of infected monocytes.

Key words: neuroinflammation; viral encephalitis; gliosis; endocannabinoids; immunohistochemistry; macaques

\section{Introduction}

Cannabinoid $\mathrm{CB}_{1}$ and $\mathrm{CB}_{2}$ receptors, endogenous ligands ("endocannabinoids"), degradative and synthesizing enzymes for those ligands, and specific mechanisms for the termination of the biochemical signal are the basic elements of the endocannabinoid system (ECS) (Porter and Felder, 2001; Freund et al., 2003). It has been hypothesized that the ECS participates in several key processes that are related to, for instance, the control of motor activity, memory, reward, nociception, emesis, and endocrine functions (Pertwee, 2000). Furthermore, a prominent role for this system has been postulated in neuroprotection as well as in acute and chronic neurodegeneration (Grundy et al., 2001; Mechoulam et al., 2002).

However, the pathophysiological role(s) of the ECS in the CNS of higher mammals remains scarcely understood. Although subtle differences exist, it is currently accepted that basic aspects

Received Sept. 22, 2004; revised Jan. 5, 2005; accepted Jan. 13, 2005.

This work was supported by Ministerio de Educación y Ciencia Grant SAF2004-00237 (J.R.) and National Institutes of Health Grants NS37654 and NS40237 (K.W.), DA09155 and NS41314 (C.J.H.), and DA11322 and DA00286 (K.M.). The technical work of Julia Molina is gratefully acknowledged.

Correspondence should be addressed to J. Romero, Laboratorio de Apoyo a la Investigación, Fundación Hospital Alcorcón, 28922 Madrid, Spain. E-mail: jromerop@fhalcorcon.es.

DOI:10.1523/JNEUROSCI.3923-04.2005

Copyright $\odot 2005$ Society for Neuroscience $\quad$ 0270-6474/05/252530-07\$15.00/0 related to cannabinoid $\mathrm{CB}_{1}$ receptors and fatty acid amide hydrolase (FAAH) distributions in the human brain are in agreement with those observed in the rat (Tsou et al., 1998b; Freund et al., 2003). Cortical regions, basal ganglia structures, the hippocampus, and the cerebellar cortex exhibit high levels of expression of $\mathrm{CB}_{1}$ receptors and FAAH (Glass et al., 1997; Tsou et al., 1998a,b; Romero et al., 2002). It is also important to note that because of the massive postmortem generation of endocannabinoids (Felder et al., 1996), few data exist on their levels in the human CNS (Schabitz et al., 2002). Finally, the selective expression of $\mathrm{CB}_{2}$ receptors in various immune cell types has been known since their discovery in 1992 (Munro et al., 1993). It is currently accepted that the ECS, mainly through $\mathrm{CB}_{2}$ receptors, participates in a wide variety of immune-related functions that range from antigen processing to macrophage migration or B-cell differentiation (Howlett et al., 2002).

Very recently, our group has reported that $\mathrm{CB}_{2}$ receptors are present in both healthy brains (Nunez et al., 2004) and Alzheimer's disease (AD) brains (Benito et al., 2003). Thus, we have described the presence of $\mathrm{CB}_{2}$ receptors in a discrete cellular subpopulation of brain macrophages, located on the external surface of blood vessels, in the brains of control patients (Nunez et al., 2004). These perivascular macrophages exhibit differential features from other types of microglia and play important roles in 
blood-brain barrier functionality (Williams et al., 2001b). This observation diverges from previous observations of rat and mouse brains (Lynn and Herkenham, 1994; Howlett et al., 2002) and suggests an additional role for the ECS in the human CNS. In addition, $\mathrm{CB}_{2}$ receptor expression is induced in activated microglial cells associated with deposits of $\beta$-amyloid peptide in $\mathrm{AD}$ (Benito et al., 2003). Additional experimental data also found profound changes in FAAH distribution in $\mathrm{AD}$ tissue samples, because both FAAH protein and enzymatic activity are significantly increased in astrocytes surrounding $\beta$-amyloid-enriched plaques. Interestingly, no changes in $\mathrm{CB}_{1}$ receptor patterns of distribution in AD samples were observed (Benito et al., 2003).

These observations suggest that the ECS undergoes dramatic changes in degenerative processes associated with neuroinflammation. This has led us to study the possible changes in specific elements of the ECS in an animal model of encephalitis.

\section{Materials and Methods}

Animals and sampling. Necropsy brain specimens from rhesus macaques (Macaca mulatta) with acquired immunodeficiency syndrome (AIDS) and simian immunodeficiency virus (SIV)-induced encephalitis (SIVE) $(n=4)$, SIV-infected animals with AIDS and without encephalitis $(n=$ 2 ), and one normal, uninfected control were used in this study. Animals were inoculated with SIVmac251 (20 ng of SIV p27) by intravenous injection. All infected animals were administered the CD8-depleting monoclonal antibody cM-T807 (5 mg/kg, i.v.) on days 6,8 , and 10 after infection. After the initial CD8 depletion, there is a rebound of CD8 Tcells. In animals with or without CD8 depletion, nearly all T-cells in SIVE brains are of the CD8 type (Kim et al., 2004). In this study, the main reason for using the $\mathrm{CD} 8$ depletion paradigm was to induce more severe encephalitis with a higher incidence. When the animals developed AIDS, they were anesthetized with ketamine- $\mathrm{HCl}$, killed by intravenous pentobarbital overdose, and exsanguinated. CNS tissues were collected in 10\% neutral buffered formalin, embedded in paraffin, and cut into 5- $\mu \mathrm{m}$ thick sections. The areas used in this study included frontal and parietal cortices. We chose these structures based on the well known changes that take place in these regions in SIVE, specifically in subcortical white matter.

Immunohistochemistry. The protocol used for the immunohistochemical staining is basically the same as described previously (Tsou et al., 1998a; Benito et al., 2003), with slight modifications. Briefly, tissue sections were deparaffinized and washed extensively in $50 \mathrm{~mm}$ potassiumPBS (KPBS), and endogenous peroxidase was blocked by incubation in peroxidase-blocking solution (Dako, Glostrup, Denmark) for $20 \mathrm{~min}$ at room temperature. To obtain a more efficient immunostaining, tissue sections were subjected to an antigen retrieval procedure (Shi et al., 2001). Briefly, sections were placed in a stainless-steel pressure cooker containing a boiling solution (Antigen Retrieval Solution; Dako). After heating under pressure for $2 \mathrm{~min}$, samples were removed and washed extensively in KPBS. Tissue sections were then incubated with the diverse primary antibodies [rabbit polyclonal anti-CB ${ }_{1}, 1: 1000$ dilution in KPBS; rabbit polyclonal anti- $\mathrm{CB}_{2}, 1: 500$ dilution in KPBS (both from Affinity BioReagents, Golden, CO); and rabbit polyclonal anti-FAAH, 1:500 dilution in KPBS (Romero et al., 2002)]. The specificity of these antibodies has been characterized previously (Romero et al., 2002; Benito et al., 2003; Nunez et al., 2004). After $24 \mathrm{~h}$ of incubation at $4^{\circ} \mathrm{C}$, sections were washed in $50 \mathrm{~mm}$ KPBS and incubated with biotinylated goat anti-rabbit antibody (1:200) at room temperature for $1 \mathrm{~h}$ followed by avidin-biotin complex (Vector Elite; Vector Laboratories, Burlingame, CA), according to the manufacturer's instructions. Visible reaction product was produced by treating the sections with $0.04 \%$ diaminobenzidine (DAB) (Dako) and $0.01 \% \mathrm{H}_{2} \mathrm{O}_{2}$, dissolved in $0.1 \mathrm{~m}$ sodium acetate. Sections were then dehydrated and sealed with coverslips. Controls for the immunohistochemistry included preabsorption and coincubation of the antibodies with the corresponding immunogenic proteins $\left(\mathrm{CB}_{1}\right.$, fusion protein against amino acids $1-100$ of human $\mathrm{CB}_{1}$ at $5 \mu \mathrm{g} / \mathrm{ml} ; \mathrm{CB}_{2}$, fusion protein against amino acids $1-33$ of human $\mathrm{CB}_{2}$ at $5 \mu \mathrm{g} / \mathrm{ml}$; FAAH, fusion protein against amino acids $561-579$ of rat FAAH at $1.25 \mu \mathrm{g} / \mathrm{ml}$ ) and incubation in the absence of primary antibody. Sections adjacent to those used in the immunohistochemical studies were used for hematoxylin and Nissl stainings. A Nikon (Tokyo, Japan) Eclipse 90i microscope and DXM1200F camera were used for the observations and photography of the slides, respectively.

Immunofluorescence. To obtain complete identification of the cellular types exhibiting FAAH or $\mathrm{CB}_{2}$ immunostainings, double-labeling studies were performed. The phenotypic markers used were as follows: glial fibrillary acidic protein (GFAP) as a prototypic marker for astrocytes (monoclonal mouse anti-human GFAP; 1:100 dilution; Dako); CD68 as a macrophage/microglia marker (monoclonal mouse anti-human CD68; 1:100 dilution; Dako); and CD3 as a T-lymphocyte marker (monoclonal mouse anti-human CD3; 1:50 dilution; Dako). We have demonstrated recently that essentially all of the CD3-positive T-cells in the brains of SIV-infected animals with SIVE are CD8 T-cells (Kim et al., 2004). The protocol included two consecutive steps: immunostaining with one of the markers mentioned and chromogenic reaction with $\mathrm{DAB}$, followed by immunofluorescence with anti- $\mathrm{CB}_{2}$ antibody, as described previously (Nunez et al., 2004).

For FAAH/GFAP colocalization, the described protocol (see above) was performed for FAAH staining by using a secondary biotinylated antibody followed by avidin-biotin amplification (Vector Laboratories) and $\mathrm{DAB}$ as chromogen. After extensive washes, sections were incubated with the anti-GFAP antibody for $24 \mathrm{~h}$ at $4^{\circ} \mathrm{C}$, followed by incubation with an Alexa 488 anti-mouse antibody conjugate (Molecular Probes, Eugene, $\mathrm{OR})$, rendering green fluorescence.

For $\mathrm{CB}_{2} / \mathrm{CD} 68$ and $\mathrm{CB}_{2} / \mathrm{CD} 3$ colocalizations, the EnVision system (Dako) was used to visualize the presence of microglia and T-lymphocytes, respectively, using $\mathrm{DAB}$ as chromogen, thus rendering brown color. Afterward, samples were incubated with anti- $\mathrm{CB}_{2}$ antibody, subsequently incubated with biotinylated anti-rabbit secondary antibody, and finally incubated with Alexa 488-streptavidin conjugate (Molecular Probes), rendering green fluorescence. A Nikon Eclipse 90i microscope and DXM1200F camera were used for the observations and photography of the slides, respectively.

Western blotting. Protein extracts were prepared from frontal cortices of one uninfected control and two SIVE monkeys that were used for immunohistochemistry. Tissues were homogenized in lysis buffer (50 mм Tris- $\mathrm{HCl}, \mathrm{pH} 8.0,150 \mathrm{~mm} \mathrm{NaCl}, 1 \% \mathrm{NP}-40)$ with $1 \times$ protease inhibitor mixture (Roche Products, Welwyn Garden City, UK). The homogenate was incubated on ice for $30 \mathrm{~min}$ and then centrifuged at $10,000 \times g$ for $30 \mathrm{~min}$ at $4^{\circ} \mathrm{C}$. The supernatant was collected, and protein concentration was determined using the BCA protein assay kit (Pierce, Rockford, IL). Twenty-five micrograms of protein extract from each sample were reduced and denatured and separated by electrophoresis through a $4-15 \%$ gradient polyacrylamide preparative gel. The proteins were transferred from the gel to Immuno-Blot polyvinylidene difluoride membrane (Bio-Rad, Hercules, CA). The membrane was washed with TBS containing $0.1 \%$ Tween 20 (TBST) and blocked in TBST containing $5 \%$ dry goat milk. Primary antibody was diluted in TBST containing 5\% dry goat milk at 1:2000 for $\mathrm{CB}_{1}$; this was incubated overnight at $4^{\circ} \mathrm{C}$ with gentle shaking. Blots were washed four times in TBST and then incubated with goat anti-rabbit HRP (1:1000; Dako) for $1 \mathrm{~h}$ at room temperature. The membrane was washed four times in TBST. Finally, the immune complex was visualized using an ECL Western Blotting kit (Amersham Biosciences, Arlington Heights, IL). The specificity of the signal was confirmed by preincubation with the immunizing peptide (1:900).

\section{Results}

Although no significant changes could be seen among control and SIV animals with AIDS and without encephalitis, clear differences were evident in the pattern of expression of some elements of the ECS in the brains of SIVE animals. For this reason, joint data from control and SIV animals without encephalitis are presented herein and compared with those from SIVE animals. 

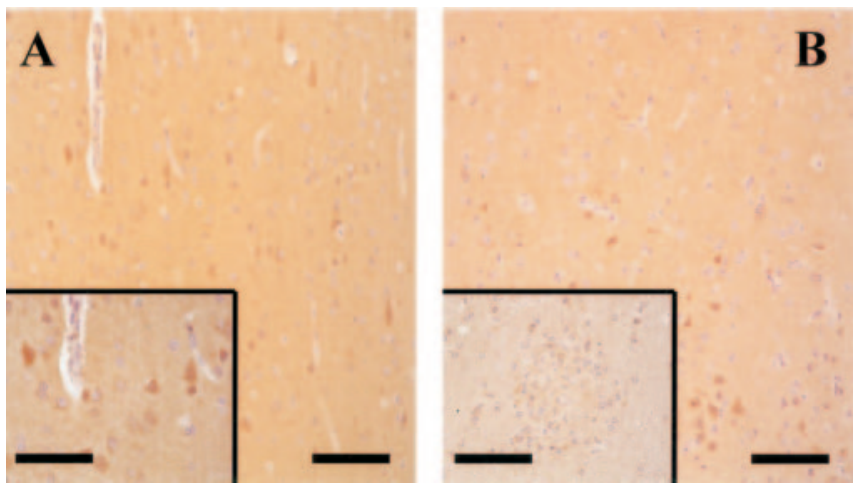

Figure 1. $\quad\left(B_{1}\right.$ immunoreactivity in brain tissue samples of frontal cortex from control $(A)$ and SIVE $(\boldsymbol{B})$ animals. In both groups, a moderate signal could be observed in pyramidal neurons ( $\boldsymbol{A}$, inset) together with a diffuse neuropilic labeling. No significant modifications were observed in SIVE animals even within cellular infiltrates in white matter areas ( $\boldsymbol{B}$, inset). Scale bars: $\boldsymbol{A}, \boldsymbol{B}, 400$ $\mu \mathrm{m}$; insets, $200 \mu \mathrm{m}$.

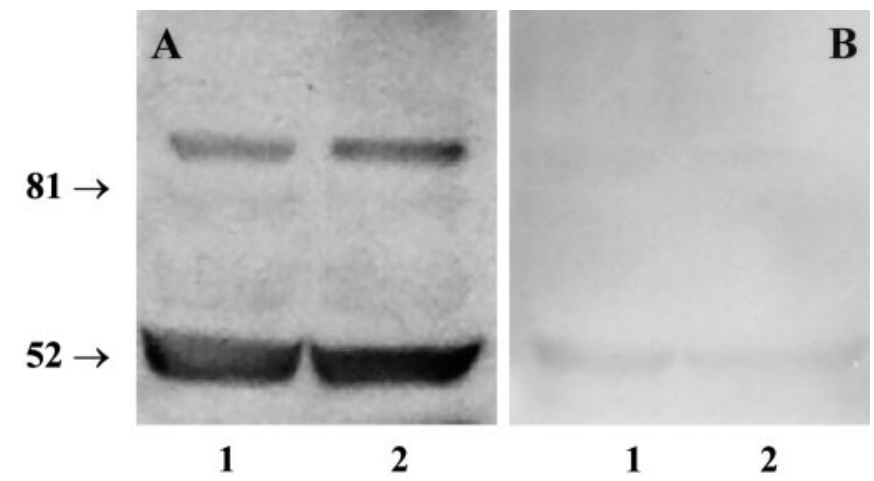

Figure 2. Western blot of $\mathrm{CB}_{1}$ immunoreactivity in cortical tissue homogenates from control $(\boldsymbol{A}$, lane 1$)$ and SIVE $(\boldsymbol{A}$, lane 2$)$ animals. Two bands of 85 and $52 \mathrm{kDa}$ were detected. Preincubation with the immunizing peptide completely prevented the signal in control ( $\boldsymbol{B}$, lane 1$)$ and SIVE ( $\boldsymbol{B}$, lane 2$)$ samples.

\section{$\mathrm{CB}_{1}$ receptors}

$\mathrm{CB}_{1}$ receptors were distributed homogeneously throughout the neuropil of the macaque cortex both in control and in SIVE animals (Fig. 1). In addition, cell bodies of pyramidal neurons were moderately stained, whereas no $\mathrm{CB}_{1}$ immunoreactivity was observed in white matter areas or in perivascular infiltrates (Fig. $1 B)$. Finally, no significant changes were noticed in the pattern of expression and/or in the amount of $\mathrm{CB}_{1}$ protein (Fig. 2) between control and SIVE samples.

\section{$\mathrm{CB}_{2}$ receptors}

Although no significant staining was observed in tissue samples from control animals (Fig. 3A), an intense level of immunolabeling could be seen in SIVE animals. This signal was circumscribed to discrete cell populations. Specifically, perivascularly located cells exhibited the highest levels of staining (Fig. 3B), and remarkably some cells were also stained in white matter areas. These $\mathrm{CB}_{2}$-positive cells surround the external surface of almost all blood vessels, independent of the diameter of the vessels (Fig. $3 B-D)$. In addition, $\mathrm{CB}_{2}$ immunostaining could be observed in cells located within cellular infiltrates (Fig. $3 E, F$ ). This signal corresponded to grouped cells and was limited to cellular infiltrates surrounding blood vessel walls, which is a well characterized feature of SIVE brains.

To define the specific cell type(s) expressing $\mathrm{CB}_{2}$ receptors in
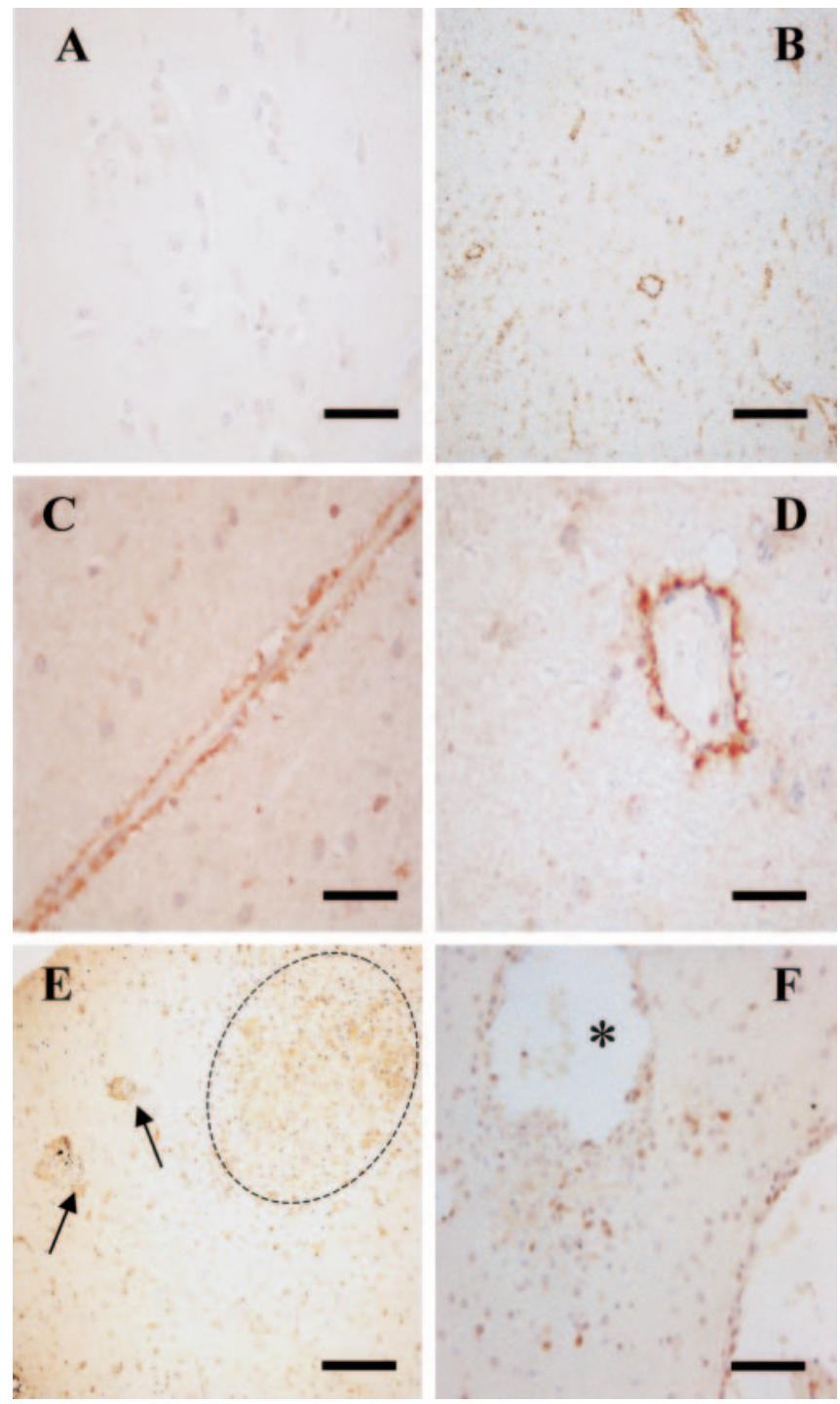

Figure 3. $\quad C_{2}$ staining in brain cortical tissue samples of the frontal cortex from control $(A)$ and SIVE ( $\boldsymbol{B}-\boldsymbol{F})$ animals. $\boldsymbol{A}$, Note the absence of any detectable signal in tissue sections from control animals compared with SIVE animals $(\boldsymbol{B})$. $\boldsymbol{B}$, Selected cells on a perivascular location show strong immunoreactivity for $\mathrm{CB}_{2}$ receptors. Longitudinal $(\boldsymbol{C})$ and transverse $(\boldsymbol{D})$ sections of blood vessels show intense signal in the outer surface of the vessel walls. $E, C_{2}$-positive cells within cellular infiltrates commonly found in perivascular areas of SIVE brains. Cells located both on incipient microglial nodules (arrows) and on well developed, mature infiltrates (dashed circle) show $\mathrm{CB}_{2}$ labeling. $\boldsymbol{F}$, High-magnification image of an incipient infiltrate in the proximity of a blood vessel wall (asterisk) showing $\mathrm{CB}_{2}$ immunoreactivity (brown color). Scale bars: $\boldsymbol{E}, 800$ $\mu \mathrm{m} ; \boldsymbol{A}, \boldsymbol{B}, 400 \mu \mathrm{m} ; \boldsymbol{C}, 200 \mu \mathrm{m} ; \boldsymbol{D}, \boldsymbol{F}, 100 \mu \mathrm{m}$.

SIVE animal tissue sections, double-labeling experiments were performed. To that end, two well known phenotypic markers were used: CD3 receptor (a marker for T-lymphocytes) and CD68 antigen (a marker for macrophages/microglia). Results obtained by this experimental approach allowed us to identify perivascular microglia and T-lymphocytes as $\mathrm{CB}_{2}$-expressing cells. Thus, CD68-positive cells located on the external surface of blood vessels as well as in perivascular cellular infiltrates also expressed $\mathrm{CB}_{2}$ receptors (Fig. $4 A-D$ ). Additionally, cell groups including numerous CD3-positive cells in SIVE lesions were also $\mathrm{CB}_{2}$ positive, thus indicating the presence of this subtype of cannabinoid receptor in T-lymphocytes (Fig. 4E,F). We have recently performed extensive double-label immunohistochemistry and found that most of the CD3 T-cells in the CNS are of the CD8 

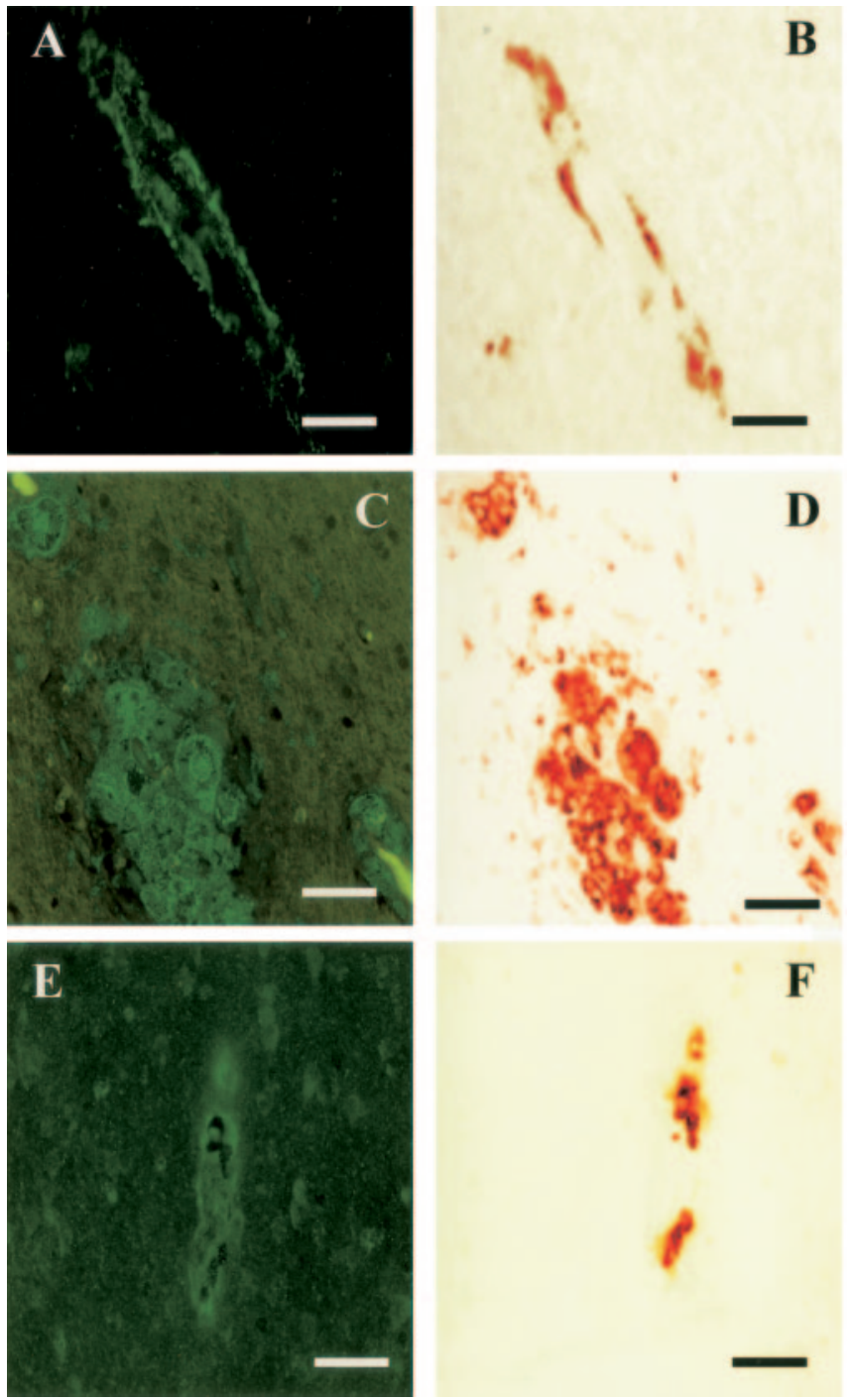

$\mathbf{F}$

Figure 4. $\quad \mathrm{CB}_{2}$ receptors are expressed by microglial cells associated with blood vessels $(A, B)$ as well as in pathological cellular infiltrates $(\boldsymbol{C}, \boldsymbol{D})$ and by T-lymphocytes $(\boldsymbol{E}, \boldsymbol{F}) . \boldsymbol{A}$, Immunofluorescent signal for $\mathrm{CB}_{2}$ receptors is located in the outer portion of a blood vessel. $\boldsymbol{B}$, CD68 immunoreactivity (a common marker of macrophages/microglia) in the same vessel shown in A. Note the partial overlap of $\mathrm{CB}_{2}$ and $\mathrm{CD} 68$ staining. $C$, Immunofluorescent signal for $\mathrm{CB}_{2}$ receptors in groups of perivascular cells. $\boldsymbol{D}$, The same groups of cells were positive for $\mathrm{CD} 68$ staining. $\boldsymbol{E}, \boldsymbol{F}$, Cellular infiltrates show strong immunoreactivity for $\mathrm{CB}_{2}(\boldsymbol{E})$ and $\mathrm{CD} 3(\boldsymbol{F})$. Note the almost total match between both patterns. Scale bars, $50 \mu \mathrm{m}$.

T-cell subset (Kim et al., 2004), suggesting that these CD8positive cells are also expressing $\mathrm{CB}_{2}$ receptors.

\section{FAAH}

Cortical gray matter regions of control and SIVE macaques showed medium to intense immunoreactivity for FAAH (Fig. 5). Pyramidal neurons exhibited a strong signal in cell bodies. Interestingly, a clear perinuclear reinforcement could be noticed, whereas dendrites and axons were weakly stained; this resembles previous data obtained in human samples (data not shown) (Romero et al., 2002).

Dramatic changes were apparent in white matter areas of the cortex, an area known to suffer extensive astrogliosis in SIVE and human immunodeficiency virus (HIV)-induced encephalitis (HIVE). Thus, although no staining for FAAH was observed in white matter from control animals, strong immunoreactivity was
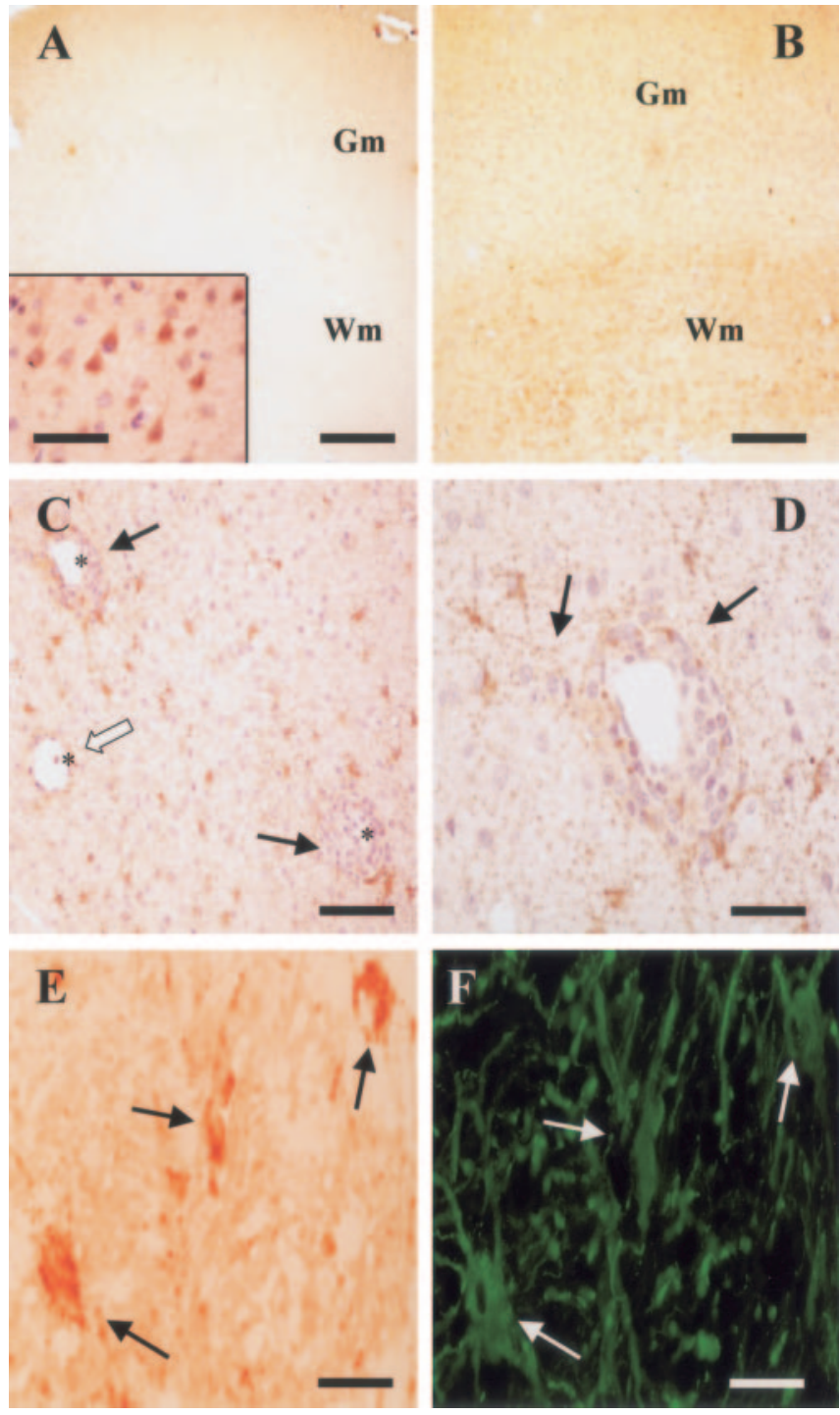

Figure 5. FAAH immunoreactivity in brain cortical tissue samples of the frontal cortex from control $(\boldsymbol{A})$ and SIVE $(\boldsymbol{B}-\boldsymbol{F})$ animals. $\boldsymbol{A}$, FAAH staining in control animals was limited to gray matter $(G \mathrm{~m})$ portions of the cortex, specifically in pyramidal neurons (inset). Note the almost complete absence of labeling in white matter areas (Wm). $\boldsymbol{B}$, FAAH immunoreactivity in SIVE was dramatically increased in white matter areas of the cortex. This increased signal corresponded to the astrogliotic process characteristic of SIVE. C, D, FAAH is massively expressed in white matter astrocytes and, remarkably, in those associated with blood vessels ( $\boldsymbol{C}$, asterisks) having perivascular infiltrates (arrows). Interestingly, a lesser degree of expression seemed to occur around those vessels lacking these pathological structures ( $\boldsymbol{C}$, white arrow). FAAH immunoreactivity was present both in somata and in astrocytic processes. $\boldsymbol{E}, \boldsymbol{F}$, FAAH immunoreactivity (black arrows) colocalizes with GFAP-positive cells (white arrows), confirming their astrocytic nature. Scale bars: $\boldsymbol{A}, \boldsymbol{B}, 800 \mu \mathrm{m} ; \boldsymbol{C}, 200 \mu \mathrm{m}$; insets in $\boldsymbol{A}, \boldsymbol{D}, 100 \mu \mathrm{m} ; \boldsymbol{E}, \boldsymbol{F}, 50 \mu \mathrm{m}$.

detected in those with SIVE (Fig. 5B-F). This signal was present in astrocytes, as demonstrated by double staining with GFAP (Fig. $5 E, F$ ). Specifically, astrocytes surrounding perivascular cellular infiltrates showed high levels of FAAH immunostaining, in contrast to those surrounding vessels lacking pathological infiltrates, which showed only a moderate staining (Fig. 5C).

\section{Discussion}

We have studied the effects of brain infection by the simian immunodeficiency virus, a lentivirus that shares many similarities with HIV-1 (Lackner, 1994; Whetter et al., 1999; Nath et al., 2000). Brain infection by these viruses is thought to produce 
long-term damaging effects, including cognitive impairment and disruption of motor capabilities (Kolson et al., 1998; Kolson and Gonzalez-Scarano, 2000; Williams and Hickey, 2002). The SIVE model is considered a good experimental approach to the study of human disease because it mimics many of its principal hallmarks (Petry and Luke, 1997).

In humans, a subset of HIV-infected patients with dementia exhibit neuropathological changes, termed HIVE, in which microglial and astroglial cells play a pivotal role (Kolson and Gonzalez-Scarano, 2000; Kaul et al., 2001). HIVE is caused by a viral infection of the brain that targets perivascular brain macrophages (Williams et al., 2001a). Histopathology includes activated brain macrophages and astrocytes, inflammatory cuffs of monocyte/macrophages, some of which are infected, activated astrocytes, and inflammatory CD8 T-lymphocytes. Because neurons themselves are not infected directly, neuronal injury is thought to occur via indirect mechanisms by factors released from activated macrophages and astrocytes.

We report the existence of profound changes in the distribution pattern of cannabinoid $\mathrm{CB}_{2}$ and $\mathrm{FAAH}$ proteins in cortical regions of macaque brains affected by SIVE. These results fit well with those that we have observed previously in $\mathrm{AD}$ tissue samples (Benito et al., 2003) in that (1) they show dramatic changes in the distribution of several components of the ECS, (2) these changes affect mainly FAAH and $\mathrm{CB}_{2}$ receptors and not $\mathrm{CB}_{1}$, (3) the observed changes seem to be related to the inflammatory process characteristic of SIVE, and (4) a clear cellular selectivity exists for these changes, because FAAH is overexpressed in astrocytes, whereas $\mathrm{CB}_{2}$ receptors are expressed abundantly in perivascular microglial cells as well as in microglial nodules and infiltrated lymphocytes. These results allow us to postulate some elements of the ECS as markers for CNS inflammation and confirm our previous observations in $\mathrm{AD}$, which show that an endocannabinoid glial system is upregulated in vivo under inflammatory conditions (Pazos et al., 2004). Furthermore, the similarities between FAAH and $\mathrm{CB}_{2}$ changes of expression in glial cells in SIVE and those observed in $\mathrm{AD}$ tissue samples suggest a common pattern of response, independent of the type of primary inflammatory insult.

The present data indicate that $C_{1}$ receptors remain unchanged in SIVE brains with respect to control brains and their presence is limited to neuronal elements of the cortex, as revealed by Western blotting and immunohistochemistry. This is in concordance with our previous data in human $\mathrm{AD}$ tissue samples (Benito et al., 2003) and seems to rule out a direct role for this subtype of cannabinoid receptors in the SIV-induced inflammatory reaction. It must be emphasized, however, that $\mathrm{CB}_{1}$ stimulation has been shown to confer neuroprotection and promote neuronal cell survival under different experimental paradigms (Guzman et al., 2002; Mechoulam et al., 2002), and thus a possible protective role for them in SIVE may be postulated. It is known that SIV and HIV do not infect neurons directly but instead productively infect microglial cells and macrophages, which then produce neurotoxic substances that ultimately kill neurons through a series of mechanisms including excitotoxicity, oxidative stress, and increases in $\mathrm{Ca}^{2+}$ levels (Kaul et al., 2001). All of these deleterious effects are known to be partially counteracted by $\mathrm{CB}_{1}$ activation (Van der Stelt et al., 2002). Interestingly, Maccarrone et al. (2004) have reported that a decrease in anandamide ( $\mathrm{CB}_{1}$ partial agonist) levels may be associated with the neurotoxicity caused by gp 120 protein, one of the main virotoxins of HIV.

On the other hand, the results presented herein indicate that cannabinoid $\mathrm{CB}_{2}$ receptors may play a critical role in CNS in- flammation. Their presence in perivascular microglial cells as well as in microglial nodules and in lymphocytes of the T type strongly suggests their involvement in several aspects of SIVE. First, we report that $\mathrm{CB}_{2}$ expression is induced in perivascular microglia as a consequence of viral infection, because control brains do not show $\mathrm{CB}_{2}$ immunoreactivity. This observation is in contrast with our previous data in control human brains that showed $\mathrm{CB}_{2}$-positive immunostaining in perivascular macrophages. As suggested in our previous work (Nunez et al., 2004), this could reflect an interspecies variation in the pattern of $\mathrm{CB}_{2}$ expression or an agonal/postmortem induction of $\mathrm{CB}_{2}$ expression in the human CNS. In any case, selective $\mathrm{CB}_{2}$ expression in this specific type of microglial cell suggests that this receptor may play a prominent role in the process of viral entry into the CNS, because perivascular microglia have been shown to be a cell type that is significantly involved in this process (Williams et al., 2001b). In this sense, it must also be emphasized that Croxford and Miller (2003) showed that viral load in the CNS is increased in the brains of mice inoculated with the Theiler virus, a murine model of multiple sclerosis, after treatment with the synthetic cannabinoid WIN55,212-2, a mixed $\mathrm{CB}_{1} / \mathrm{CB}_{2}$ agonist (Howlett et al., 2002).

Second, it is not surprising that $\mathrm{CB}_{2}$ receptors are present in microglial nodules. These cellular accumulations are one of the hallmarks of SIVE and HIVE. In addition, $\mathrm{CB}_{2}$ activation is currently considered a major factor in microglial function (Walter et al., 2003; Carrier et al., 2004) and, remarkably, has been shown to mediate the production of chemotactic substances for monocytes that are key factors in their recruitment into the brain. Klegeris et al. (2003) have reported that $\mathrm{CB}_{2}$ agonists decrease the production of proinflammatory substances by an activated human microglial cell line. Conversely, two groups have shown recently that $\mathrm{CB}_{2}$ activation also promotes microglial migration and proliferation (Walter et al., 2003; Carrier et al., 2004). Furthermore, $\mathrm{CB}_{2}$ activation enhances human macrophage-like and peripheral blood monocyte migration after $\mathrm{CB}_{2}$ activation (Derocq et al., 2000; Kishimoto et al., 2003).

Third, to our knowledge, this report is the first showing that $\mathrm{CB}_{2}$ receptors are present in peripheral cells that have infiltrated the CNS as a consequence of a pathological process. We demonstrate here that T-lymphocytes express this receptor in SIVE brains as a consequence of the viral CNS infection. Lymphocyte infiltration in tissues is a common feature in many forms of inflammation, and specifically in viral encephalitis, for which we and others have demonstrated a significant accumulation of CD8-positive T-lymphocytes that are likely SIV antigen specific (Kim et al., 2004). Although no conclusive data exist on the role of $\mathrm{CB}_{2}$ receptors in lymphocyte function (Grundy et al., 2001), these receptors are known to be expressed by peripheral T-lymphocytes, although in low levels. Their presence in these cells in the brains of SIVE animals is highly suggestive of a prominent role in CNS infiltration and could be a consequence of an upregulation process linked to brain invasion by these cells. In this sense, regulation of $\mathrm{CB}_{2}$ expression under different pathophysiological conditions has been reported previously in other experimental paradigms (Sanchez et al., 2001; Jorda et al., 2003). Additional experiments should clarify this point.

Finally, a remarkable selectivity for FAAH expression in astrocytes was observed in SIVE samples. This feature matches well with previous data from AD human samples in which FAAH expression and activity were greatly enhanced in astrocytes located in the vicinity of neuritic plaques. Although tissue samples from control animals exhibited a wide distribution of FAAH in 
principal neurons of the cortex (mainly pyramidal neurons), a massive expression of this enzyme in hypertrophied astrocytes was evident in SIVE samples. Furthermore, FAAH-positive astrocytes were found predominantly in perivascular regions and specifically in areas of cellular infiltration. It is currently thought that astrocytes become hypertrophied and hyperplastic in those brain regions in which an inflammatory process takes place and specifically that astrocytic processes densely infiltrate these areas as part of a concerted anti-inflammatory endogenous response (WyssCoray and Mucke, 2002). In our opinion, the presence of FAAH in these cells is highly suggestive of a direct involvement of FAAH in the inflammatory process linked to SIVE. In addition, astrocytes are known to play a regulatory role in HIV-1 encephalitis by dampening the overexpression of eicosanoids, platelet-activating factor, and tumor necrosis factor- $\alpha$ by activated HIV-1 monocytes (Minagar et al., 2002); FAAH overexpressed in glial cells could partially counteract some of these beneficial processes (Weber et al., 2004).

In summary, we report the existence of profound alterations in the pattern of expression of $\mathrm{CB}_{2}$ receptors and $\mathrm{FAAH}$ in the brain of macaques with SIVE. These changes are linked to the inflammatory process and suggest a prominent role for the ECS in glial activation under pathological conditions.

\section{References}

Benito C, Nunez E, Tolon RM, Carrier EJ, Rabano A, Hillard CJ, Romero J (2003) Cannabinoid $\mathrm{CB}_{2}$ receptors and fatty acid amide hydrolase are selectively overexpressed in neuritic plaque-associated glia in Alzheimer's disease brains. J Neurosci 23:11136-11141.

Carrier EJ, Kearn CS, Barkmeier AJ, Breese NM, Yang W, Nithipatikom K, Pfister SL, Campbell WB, Hillard CJ (2004) Cultured rat microglial cells synthesize the endocannabinoid 2-arachidonylglycerol, which increases proliferation via a $\mathrm{CB}_{2}$ receptor-dependent mechanism. Mol Pharmacol 65:999-1007.

Croxford JL, Miller SD (2003) Immunoregulation of a viral model of multiple sclerosis using the synthetic cannabinoid R+WIN55,212. J Clin Invest 111:1231-1240.

Derocq JM, Jbilo O, Bouaboula M, Segui M, Clere C, Casellas P (2000) Genomic and functional changes induced by the activation of the peripheral cannabinoid receptor $\mathrm{CB}_{2}$ in the promyelocytic cells HL-60. Possible involvement of the $\mathrm{CB}_{2}$ receptor in cell differentiation. J Biol Chem 275:15621-15628.

Felder CC, Nielsen A, Briley EM, Palkovits M, Priller J, Axelrod J, Nguyen DN, Richardson JM, Riggin RM, Koppel GA, Paul SM, Becker GW (1996) Isolation and measurement of the endogenous cannabinoid receptor agonist, anandamide, in brain and peripheral tissues of human and rat. FEBS Lett 393:231-235.

Freund TF, Katona I, Piomelli D (2003) Role of endogenous cannabinoids in synaptic signaling. Physiol Rev 83:1017-1066.

Glass M, Dragunow M, Faull RL (1997) Cannabinoid receptors in the human brain: a detailed anatomical and quantitative autoradiographic study in the fetal, neonatal and adult human brain. Neuroscience 77:299-318.

Grundy RI, Rabuffetti M, Beltramo M (2001) Cannabinoids and neuroprotection. Mol Neurobiol 24:29-51.

Guzman M, Sanchez C, Galve-Roperh I (2002) Cannabinoids and cell fate. Pharmacol Ther 95:175-184.

Howlett AC, Barth F, Bonner TI, Cabral G, Casellas P, Devane WA, Felder CC, Herkenham M, Mackie K, Martin BR, Mechoulam R, Pertwee RG (2002) International Union of Pharmacology. XXVII. Classification of cannabinoid receptors. Pharmacol Rev 54:161-202.

Jorda MA, Rayman N, Valk P, De Wee E, Delwel R (2003) Identification, characterization, and function of a novel oncogene: the peripheral cannabinoid receptor Cb2. Ann NY Acad Sci 996:10-16.

Kaul M, Garden GA, Lipton SA (2001) Pathways to neuronal injury and apoptosis in HIV-associated dementia. Nature 410:988-994.

Kim WK, Corey S, Chesney G, Knight H, Klumpp S, Wüthrich C, Letvin NL, Koralnik IJ, Lackner AA, Williams K (2004) Identification of T lymphocytes in simian immunodeficiency virus encephalitis: distribution of
$\mathrm{CD} 8+\mathrm{T}$ cells in association with central nervous system vessels and virus. J Neurovirol 10:315-325.

Kishimoto S, Gokoh M, Oka S, Muramatsu M, Kajiwara T, Waku K, Sugiura $\mathrm{T}$ (2003) 2-Arachidonoylglycerol induces the migration of HL-60 cells differentiated into macrophage-like cells and human peripheral blood monocytes through the cannabinoid $\mathrm{CB}_{2}$ receptor-dependent mechanism. J Biol Chem 278:24469-24475.

Klegeris A, Bissonnette CJ, McGeer PL (2003) Reduction of human monocytic cell neurotoxicity and cytokine secretion by ligands of the cannabinoid-type $\mathrm{CB}_{2}$ receptor. Br J Pharmacol 139:775-786.

Kolson DL, Gonzalez-Scarano F (2000) HIV and HIV dementia. J Clin Invest 106:11-13.

Kolson DL, Lavi E, Gonzalez-Scarano F (1998) The effects of human immunodeficiency virus in the central nervous system. Adv Virus Res 50:1-47.

Lackner AA (1994) Pathology of simian immunodeficiency virus induced disease. Curr Top Microbiol Immunol 188:35-64.

Lynn AB, Herkenham M (1994) Localization of cannabinoid receptors and nonsaturable high-density cannabinoid binding sites in peripheral tissues of the rat: implications for receptor-mediated immune modulation by cannabinoids. J Pharmacol Exp Ther 268:1612-1623.

Maccarrone M, Piccirilli S, Battista N, Del Duca C, Nappi G, Corasaniti MT, Finazzi-Agro A, Bagetta G (2004) Enhanced anandamide degradation is associated with neuronal apoptosis induced by the HIV-1 coat glycoprotein gp120 in the rat neocortex. J Neurochem 89:1293-1300.

Mechoulam R, Panikashvili D, Shohami E (2002) Cannabinoids and brain injury: therapeutic implications. Trends Mol Med 8:58-61.

Minagar A, Shapshak P, Fujimura R, Ownby R, Heyes M, Eisdorfer C (2002) The role of macrophage/microglia and astrocytes in the pathogenesis of three neurologic disorders: HIV-associated dementia, Alzheimer disease, and multiple sclerosis. J Neurol Sci 202:13-23.

Munro S, Thomas KL, Abu-Shaar M (1993) Molecular characterization of a peripheral receptor for cannabinoids. Nature 365:61-65.

Nath BM, Schumann KE, Boyer JD (2000) The chimpanzee and other nonhuman-primate models in HIV-1 vaccine research. Trends Microbiol 8:426-431.

Nunez E, Benito C, Pazos MR, Barbachano A, Fajardo O, Gonzalez S, Tolon RM, Romero J (2004) Cannabinoid CB(2) receptors are expressed by perivascular microglial cells in the human brain: an immunohistochemical study. Synapse 53:208-213.

Pazos MR, Nunez E, Benito C, Tolon RM, Romero J (2004) Role of the endocannabinoid system in Alzheimer's disease: new perspectives. Life Sci 75:1907-1915.

Pertwee RG (2000) Cannabinoid receptor ligands: clinical and neuropharmacological considerations, relevant to future drug discovery and development. Expert Opin Invest Drugs 9:1553-1571.

Petry H, Luke W (1997) Infection of macaque monkeys with simian immunodeficiency virus: an animal model for neuro-AIDS. Intervirology 40:112-121.

Porter AC, Felder CC (2001) The endocannabinoid nervous system: unique opportunities for therapeutic intervention. Pharmacol Ther 90:45-60.

Romero J, Hillard CJ, Calero M, Rabano A (2002) Fatty acid amide hydrolase localization in the human central nervous system: an immunohistochemical study. Brain Res Mol Brain Res 100:85-93.

Sanchez C, De Ceballos ML, Del Pulgar TG, Rueda D, Corbacho C, Velasco G, Galve-Roperh I, Huffman JW, Cajal S, Guzman M (2001) Inhibition of glioma growth in vivo by selective activation of the $\mathrm{CB}(2)$ cannabinoid receptor. Cancer Res 61:5784-5789.

Schabitz WR, Giuffrida A, Berger C, Aschoff A, Schwaninger M, Schwab S, Piomelli D (2002) Release of fatty acid amides in a patient with hemispheric stroke: a microdialysis study. Stroke 33:2112-2114.

Shi SR, Cote RJ, Taylor CR (2001) Antigen retrieval techniques: current perspectives. J Histochem Cytochem 49:931-937.

Tsou K, Brown S, Sanudo-Pena MC, Mackie K, Walker JM (1998a) Immunohistochemical distribution of cannabinoid $\mathrm{CB}_{1}$ receptors in the rat central nervous system. Neuroscience 83:393-411.

Tsou K, Nogueron MI, Muthian S, Sanudo-Pena MC, Hillard CJ, Deutsch DG, Walker JM (1998b) Fatty acid amide hydrolase is located preferentially in large neurons in the rat central nervous system as revealed by immunohistochemistry. Neurosci Lett 254:137-140.

Van der Stelt M, Veldhuis WB, Maccarrone M, Bar PR, Nicolay K, Veldink 
GA, Di Marzo V, Vliegenthart JF (2002) Acute neuronal injury, excitotoxicity, and the endocannabinoid system. Mol Neurobiol 26:317-346.

Walter L, Franklin A, Witting A, Wade C, Xie Y, Kunos G, Mackie K, Stella N (2003) Nonpsychotropic cannabinoid receptors regulate microglial cell migration. J Neurosci 23:1398-1405.

Weber A, Ni J, Ling KH, Acheampong A, Tang-Liu DD, Burk R, Cravatt BF, Woodward D (2004) Formation of prostamides from anandamide in FAAH knockout mice analyzed by HPLC with tandem mass spectrometry. J Lipid Res 45:757-763.

Whetter LE, Ojukwu IC, Novembre FJ, Dewhurst S (1999) Pathogenesis of simian immunodeficiency virus infection. J Gen Virol 80:1557-1568.

Williams K, Corey S, Westmoreland SV, Pauley D, Knight H, deBakker C,
Alvarez X, Lackner AA (2001a) Perivascular macrophages are the primary cell type productively infected by simian immunodeficiency virus in the brains of macaques: implications for the neuropathogenesis of AIDS. J Exp Med 193:905-915.

Williams K, Alvarez X, Lackner AA (2001b) Central nervous system perivascular cells are immunoregulatory cells that connect the CNS with the peripheral immune system. Glia 36:156-164.

Williams KC, Hickey WF (2002) Central nervous system damage, monocytes and macrophages, and neurological disorders in AIDS. Annu Rev Neurosci 25:537-562.

Wyss-Coray T, Mucke L (2002) Inflammation in neurodegenerative disease- a double-edged sword. Neuron 35:419-432. 